University of Nebraska - Lincoln

DigitalCommons@University of Nebraska - Lincoln

Agronomy \& Horticulture -- Faculty Publications

Agronomy and Horticulture Department

2001

Performance of INTERCOM for predicting corn- velvetleaf interference across north-central United States

John L. Lindquist

University of Nebraska-Lincoln, jlindquist1@unl.edu

Follow this and additional works at: https://digitalcommons.unl.edu/agronomyfacpub

Part of the Plant Sciences Commons

Lindquist, John L., "Performance of INTERCOM for predicting corn- velvetleaf interference across northcentral United States" (2001). Agronomy \& Horticulture -- Faculty Publications. 406.

https://digitalcommons.unl.edu/agronomyfacpub/406

This Article is brought to you for free and open access by the Agronomy and Horticulture Department at DigitalCommons@University of Nebraska - Lincoln. It has been accepted for inclusion in Agronomy \& Horticulture -Faculty Publications by an authorized administrator of DigitalCommons@University of Nebraska - Lincoln. 


\section{Performance of INTERCOM for predicting corn- velvetleaf interference across north-central United States}

John L. Lindquist

Department of Agronomy, University of Nebraska, Lincoln NE, 68583-0817; jlindquist1@unl.edu

\begin{abstract}
Cost-effective weed management requires accurate estimates of yield and the potential yield loss resulting from weed infestations. However, crop yield and the effects of weeds are highly variable across years and locations. Ecophysiological models may be useful for predicting the effects of environment and management on crop and weed growth and competitive ability. Ability of the model INTERCOM to predict corn (Zea mays) growth and yield, velvetleaf (Abutilon theophrasti) interference on corn yield loss, and single-year economic threshold velvetleaf density $\left(\mathrm{T}_{e}\right)$ was evaluated using 13 data sets collected in four states. Predicted and observed monoculture corn total aboveground biomass and leaf area index were in close agreement for most of the growing season. Predicted and observed weed-free corn yields were in agreement for yields ranging from 8 to $13 \mathrm{Mg} \mathrm{ha}^{-1}$ but were over- and underpredicted under low-yielding and near-optimal production conditions, respectively. Predicted and observed corn yield loss agreed well across the full range of observed velvetleaf densities for five to nine location years, depending on the performance criterion used. Estimates of $T_{e}$ calculated from predicted weed-free yield and yield loss relationships were an average of $6 \%$ smaller than those calculated from observed data, indicating that the model predicts a conservative value of $T_{e}$ in most cases. Although results are encouraging, they indicate that further research is needed to improve the capacity of INTERCOM for predicting weed-free yield and corn-velvetleaf interference.
\end{abstract}

Nomenclature: Corn, Zea mays L.; velvetleaf, Abutilon theophrasti Medic. ABUTH.

Key words: Crop modeling, competition, ecophysiology, leaf area index, simulation, ABUTH.
Cost-effective decisions about weed control require adequate understanding of the potential costs and benefits of various management options. Use of bioeconomic models in the decision-making process is a central component of integrated weed management (IWM) (Swinton and King 1994; Wilkerson et al. 1990). Decision rules in bioeconomic models rely on accurate prediction of crop loss due to weed interference (Coble and Mortensen 1992; Jordan 1992; Maxwell 1992). Current bioeconomic models predict crop yield loss from weed density with an empirical relationship. Unfortunately, corn yield loss-weed density relationships varied greatly among years and locations (Knezevic et al. 1994, 1995; Lindquist et al. 1996, 1999). Instability of interference relationships undermines the utility of bioeconomic models for improving weed management decisions.

Empirical interference relationships do not account for the influence of weather, edaphic factors, or management or their interaction on crop-weed competition. Improved methods for predicting the effects of environment and management on crop and weed growth and their competitive interactions are needed. Simulation models have been useful for predicting the influence of environment on monoculture crop growth and yield (Boote et al. 1996; Kiniry et al. 1997). Several models of crop-weed competition for growth-limiting resources are now available (Caton et al. 1999a, 1999b, 1999c; Graf et al. 1990; Graf and Hill 1992; Kiniry et al. 1992; Kropff and van Laar 1993; Kropff et al.
1994; Ryel et al. 1990; Wilkerson et al. 1990). However, the capacity of these models to predict corn-weed mixtures in multiple environments has not been evaluated.

INTERCOM was developed to simulate competition for light and soil water between sugar beet (Beta vulgaris L.) and common lambsquarters (Chenopodium album L.) (Kropff and Spitters 1992; Kropff et al. 1992; Kropff and van Laar 1993). The model has since been modified to simulate competition for light between rice (Oryza sativa L.) and several weed species (Caton et al. 1999a, 1999b, 1999c; Kropff et al. 1994; Lindquist and Kropff 1996). INTERCOM simulates growth of single or multiple plant species on a daily time step using inputs for population density, date of seeding and emergence, various cultivar-specific parameters, site latitude, and common weather data. Phenological development depends upon the accumulation of thermal units (TU). Absorption of photosynthetic photon flux (PPF) is calculated from total solar radiation, the extinction coefficient, LAI, and vertical distribution of leaf area of each species. Single leaf $\mathrm{CO}_{2}$ assimilation is calculated as a function of absorbed PPF and integrated over five canopy heights and three times of day to obtain a gross daily growth increase that is then reduced by respiration costs to obtain the net daily growth increase. New growth is then partitioned to various organ groups using empirical relationships. After adding new leaf biomass, LAI is calculated as the product of total leaf biomass and specific leaf area. Spe- 


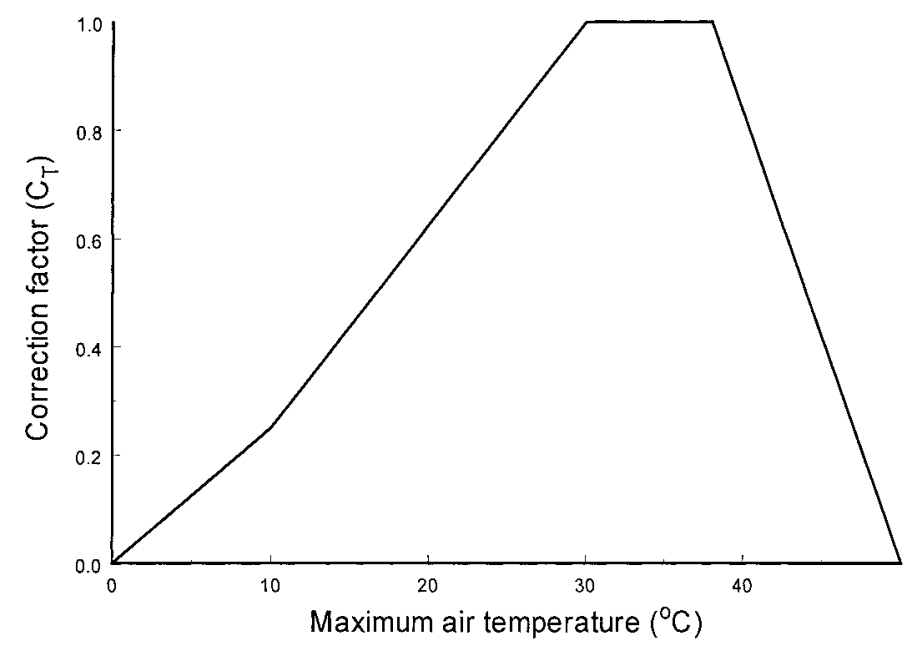

Figure 1. Correction factor $\left(\mathrm{C}_{T}\right)$ used to adjust light-saturated $\mathrm{CO}_{2}$ assimilation in response to maximum daily air temperature. The same relationship was used for both corn and velvetleaf. Values used as input are 0, 0; $10,0.25 ; 30,1 ; 38,1 ; 50,0$, where the first number in the pair is temperature and the second the $\mathrm{C}_{T}$ value.

cifics of these calculations were described in detail elsewhere (Kropff and van Laar 1993).

Velvetleaf is one of the most troublesome weeds in corn throughout the United States (Bridges 1992). Corn yield loss in response to velvetleaf interference was recently studied by a number of researchers across the north-central United States (Lindquist et al. 1996). Their data sets provided a unique opportunity for testing the performance of INTERCOM for predicting the effects of weed interference on corn yield. The objective was to test the accuracy of INTER$\mathrm{COM}$ for predicting corn monoculture growth and yield, the corn yield loss-velvetleaf density relationship, and calculated single-year economic threshold velvetleaf density in multiple environments.

\section{Materials and Methods}

\section{INTERCOM Parameter Inputs}

INTERCOM was modified and parameterized for corn and velvetleaf based on the work of Lindquist and Mortensen (1999). Two additional modifications were made within INTERCOM to account for the effects of temperature on $\mathrm{CO}_{2}$ assimilation and corn height growth. Light-saturated $\mathrm{CO}_{2}$ assimilation rate $\left(A_{\max }\right)$ varies as a function of leaf nitrogen content and maximum daily temperature.

$$
A_{\text {max }}=f\left(\mathrm{~N}_{\mathrm{L}}\right) \mathrm{C}_{T}\left(T_{\text {max }}\right)
$$

The $f\left(\mathrm{~N}_{\mathrm{L}}\right)$ is the functional relationship between $\mathrm{CO}_{2}$ assimilation rate and leaf nitrogen content $\left(\mathrm{N}_{\mathrm{L}}\right.$, Lindquist and Mortensen 1999), and $C_{T}$ is a proportional correction factor that varies as a function of maximum daily air temperature ( $T_{\max }$, Figure 1). The relationship presented in Figure 1 was derived from that shown by de Wit et al. (1978) and is supported in part by Tollenaar (1989). Complete data were not available for velvetleaf. However, because velvetleaf grows well at high temperatures (Coleman et al. 1991; Patterson 1992), the same relationship was used for both velvetleaf and corn.

Kropff (1993) used a logistic equation to predict height
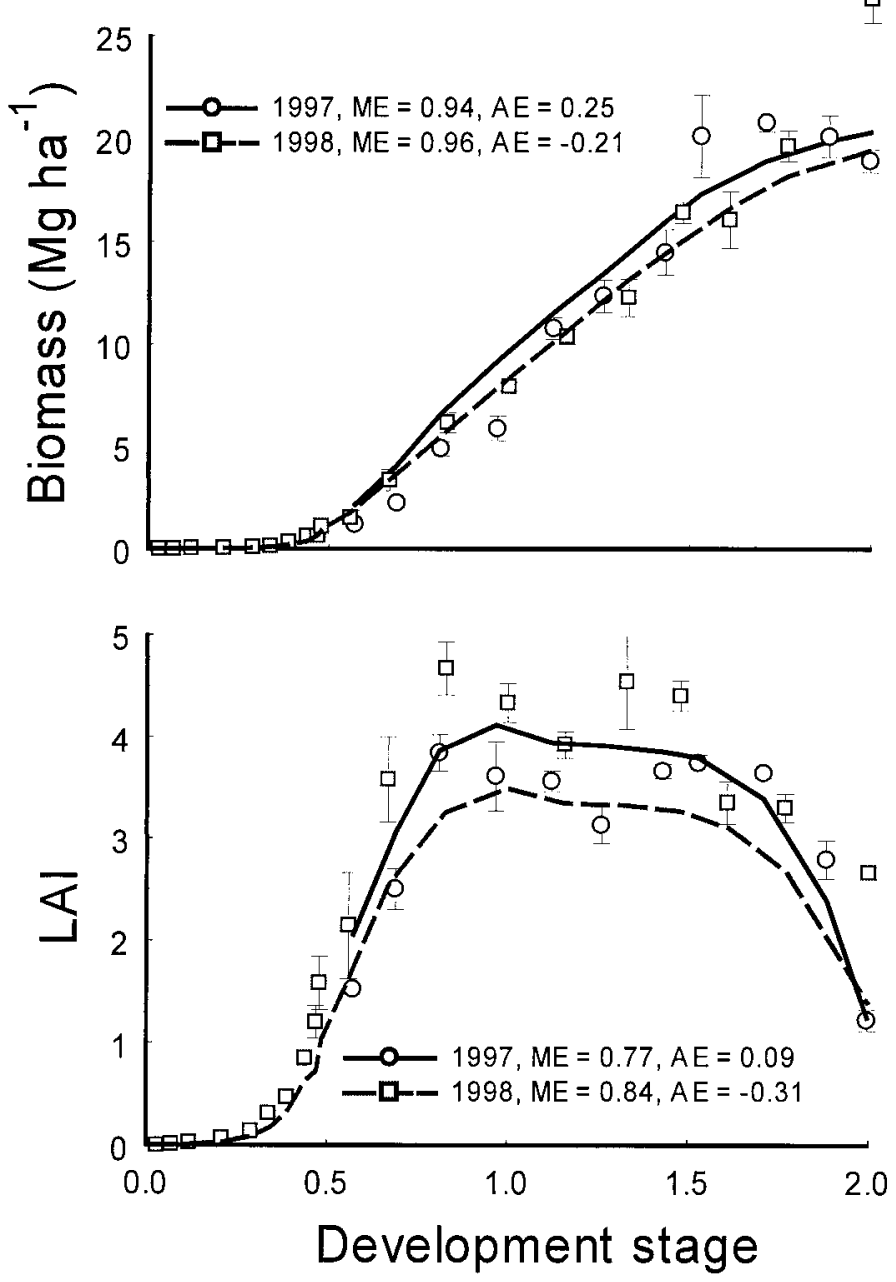

FIGURE 2. Observed (symbols with standard errors) and simulated (lines) total aboveground biomass and LAI for monoculture corn as a function of development stage (DVS, $0=$ emergence, $1=$ anthesis, $2=$ physiological maturity). ME, modeling efficiency; AE, average normalized error across all sampling dates.

as a function of thermal units $\left([\mathrm{C} \mathrm{d}]^{-1}\right)-\min \left(30-T_{\text {base }}\right.$, $\left.\max \left[0, T_{\text {ave }}-T_{\text {base }}\right]\right)$, where $T_{\text {base }}$ is the base temperature for development, $T_{\text {ave }}$ is the daily average temperature ( $T_{\max }$ $\left.+T_{\min }\right) / 2$-accumulated from emergence to physiological maturity. Phenological development is determined by thermal time within INTERCOM; however, the rate of developmental changes depends on the maturity class of the hybrid used (Kiniry et al. 1997). Therefore, development stage (DVS) was substituted for TU as the predictor of corn height growth because DVS is automatically adjusted for development rate. Corn height data of Lindquist and Mortensen (1999) were reanalyzed using DVS as the independent variable to obtain appropriate parameter inputs (analysis not shown, but estimates of maximum height, $\mathrm{HT}_{\mathrm{m}}$, and two shape coefficients, $H_{\mathrm{a}}$ and $H_{\mathrm{b}}$, are listed in Table 2).

\section{Experimental Data}

Monoculture corn growth and leaf area index were measured under field conditions at the University of Nebraska Agricultural Research and Development Center (ARDC) at 
Havelock, NE, in 1997 and on a farmer's field near Sterling, $\mathrm{NE}$, in 1998. A pair of plants was periodically sampled at five locations within a field under general rain-fed production at the ARDC Havelock farm. Leaves of each pair were removed, leaf area was measured, and whole-plant samples were dried to constant weight. Population counts were made on a 2-m section of row centered on the sampling location of each pair (average population was 52,000 plants ha ${ }^{-1}$ ). Two meters of row were periodically sampled in the farmer's field near Sterling, NE. This field was furrow irrigated, and corn yielded at least $15 \mathrm{Mg} \mathrm{ha}^{-1}$ of grain. Leaves were removed, leaf area was measured, and whole-plant samples were dried to constant weight. Population counts were obtained for the entire area sampled throughout the growing season (average population was 66,000 plants ha ${ }^{-1}$ ).

Multiyear field experiments were established at six locations across the north-central United States to measure corn yield response to a range of velvetleaf population densities (Lindquist et al. 1996; Lindquist and Mortensen 1998). Experiments were established using a randomized complete block design with three to five replicates, depending on location. A locally adapted corn hybrid was seeded in rows spaced $0.76 \mathrm{~m}$ apart at recommended population densities. Velvetleaf was seeded into the crop row with a push planter immediately after corn seeding and subsequently thinned to a range of evenly spaced target densities. Actual corn and velvetleaf densities were counted in $3 \mathrm{yr}$ of the Nebraska research and in both years of the Colorado study. Four of six rows were harvested in each experimental unit to measure grain yield, which was adjusted to $15.5 \%$ moisture. Further details on experimental design, planting date, corn population density, and measured yield for each study are presented elsewhere (Lindquist et al. 1996, Lindquist and Mortensen 1998). Experiments were conducted under rain-fed conditions, except those at Fort Collins, CO, which were gravity irrigated, and at Mead, NE, which were sprinkler irrigated.

\section{Simulation Input}

Simulations were conducted using year- and location-specific information on planting date, date of $50 \%$ emergence, plant density, and rate of development where available. In many cases, dates of emergence and development rate were not available, so emergence of both species was assumed to have occurred $7 \mathrm{~d}$ after planting. Rate of corn development was adjusted for maturity based on latitude (Kiniry et al. 1997), with slight modifications if those development rates resulted in inappropriately long growing seasons (Table 1). Lindquist and Mortensen (1999) showed that velvetleaf development was similar to that of corn, so development rates were considered identical for corn and velvetleaf. Where actual population counts were not available, target density was used as model input. Species-specific parameter inputs were held constant for all simulations (Table 2).

Weather data used for all simulations were obtained from an automated weather station located as close to each experimental location (typically within $1 \mathrm{~km}$ ) as possible. Data from the farmer's field at Sterling, NE, were obtained from a portable weather station placed at the edge of the field. Data for other Nebraska locations and the South Dakota location were obtained from the High Plains Climate Center (Lincoln, NE), and those from Colorado were obtained from the Colorado Climate Center. Michigan State Univer-
TABLE 1. Date of emergence (DOE) and thermal units accumulated between emergence and anthesis $\left(\mathrm{TU}_{\mathrm{v}}\right)$ and between anthesis and physiological maturity $\left(\mathrm{TU}_{\mathrm{r}}\right)$.

\begin{tabular}{llccccc}
\hline Site & & Latitude & Year & DOE $^{\mathrm{a}}$ & $\mathrm{TU}_{\mathrm{v}}^{\mathrm{b}}$ & $\mathrm{TU}_{\mathrm{r}}$ \\
\hline $\mathrm{NE}$ & (Lincoln) & 40.9 & 1988 & 144 & 725 & 875 \\
& (Lincoln) & 40.9 & 1991 & 137 & 800 & 800 \\
& (Lincoln) & 40.9 & 1992 & 135 & 725 & 555 \\
& (Lincoln) & 40.9 & 1993 & 138 & 725 & 675 \\
& (Mead) & 41.2 & 1994 & 133 & 730 & 735 \\
& (Mead) & 41.2 & 1995 & 148 & 745 & 735 \\
& (Mead) & 41.2 & 1996 & 140 & 725 & 620 \\
& (Lincoln) & 40.9 & 1997 & 135 & 725 & 750 \\
SD & (Brookings, 1) & 44.3 & 1992 & 135 & 500 & 350 \\
& & 44.3 & 1993 & 153 & 500 & 450 \\
SD & (Beresford, 2) & 43.1 & 1992 & 131 & 500 & 485 \\
$\mathrm{MI}$ & (East Lansing) & 42.7 & 1992 & 140 & 590 & 400 \\
& & 42.7 & 1993 & 146 & 590 & 520 \\
$\mathrm{CO}$ & (Fort Collins) & 40.7 & 1993 & 130 & 550 & 400 \\
& & 40.7 & 1994 & 133 & 650 & 550 \\
\hline
\end{tabular}

${ }^{a}$ Locations where date of emergence was recorded were NE 1995 and 1996 and MI 1992 and 1993. Elsewhere, date of emergence was estimated to be $7 \mathrm{~d}$ after planting.

b Locations where dates of anthesis and maturity were recorded were NE 1995 and 1996. Elsewhere, dates were estimated using average date of anthesis and maturity for that year.

sity Agricultural climatologists provided daily minimum and maximum temperatures and precipitation, and the Midwest Climate Center provided total solar radiation, average relative humidity, and wind speed from a station at Lansing, MI.

\section{Statistical Methods and Performance Criterion}

Interference relationships were quantified by fitting the loss in yield $\left(Y_{\mathrm{L}}\right)$ from velvetleaf interference on weed density using $Y_{\mathrm{L}}=I N /(1+I N / A)$, where $I$ is yield loss as weed density $(N)$ approaches zero, and $A$ is the asymptote (Cousens 1985). Both predicted and observed yield loss were fit on velvetleaf density using nonlinear regression analysis. Estimates of $I, A$, and the residual mean square error (RMSE) of the regression are reported in Table 3. A single-year economic threshold weed density $\left(\mathrm{T}_{\mathrm{e}}\right)$, the weed density at which management cost equals the value of yield loss if weeds are left unmanaged, can be defined using (Cousens 1987).

$$
\mathrm{T}_{\mathrm{e}}=C / Y_{\mathrm{wf}} P\left(Y_{\mathrm{L}, 0}-Y_{\mathrm{L}, \mathrm{m}}\right)
$$

$C$ is total cost of implementing the management practice (\$ $\left.\mathrm{ha}^{-1}\right), Y_{\mathrm{wf}}$ is weed-free crop yield $\left(\mathrm{kg} \mathrm{ha}^{-1}\right), P$ is the price obtained for the grain $\left(\$ \mathrm{~kg}^{-1}\right), Y_{\mathrm{L}, 0}$ is yield loss without management, and $Y_{\mathrm{L}, \mathrm{m}}$ is yield loss after management has removed $E_{\mathrm{f}} N$ weeds (where $E_{\mathrm{f}}$ is management efficacy). Substitution of Cousens (1985) yield loss model into Equation 2 and rearrangement results in a quadratic equation

$$
\left.0=\left(1-E_{\mathrm{f}}\right)\left(\mathrm{T}_{\mathrm{e}} I / A\right)^{2}+2-E_{\mathrm{f}}-Y_{\mathrm{wf}} P A E_{\mathrm{f}} / C\right)\left(\mathrm{T}_{\mathrm{e}} I / A\right)+1
$$

that can be solved algebraically for $T_{e}$ (Cardina et al. 1995; Cousens 1987). $T_{\mathrm{e}}$ was calculated for each location-year using observed and predicted estimates of $I, A$, and $Y_{\mathrm{wf}}$ and constant values of $C\left(\$ 49.4 \mathrm{ha}^{-1}\right), P\left(\$ 0.1021 \mathrm{~kg}^{-1}\right)$, and $E_{\mathrm{f}}$ (0.9) (Lindquist et al. 1999). 
TABLE 2. Corn 'Pioneer 3379' and velvetleaf parameters used as inputs for INTERCOM.

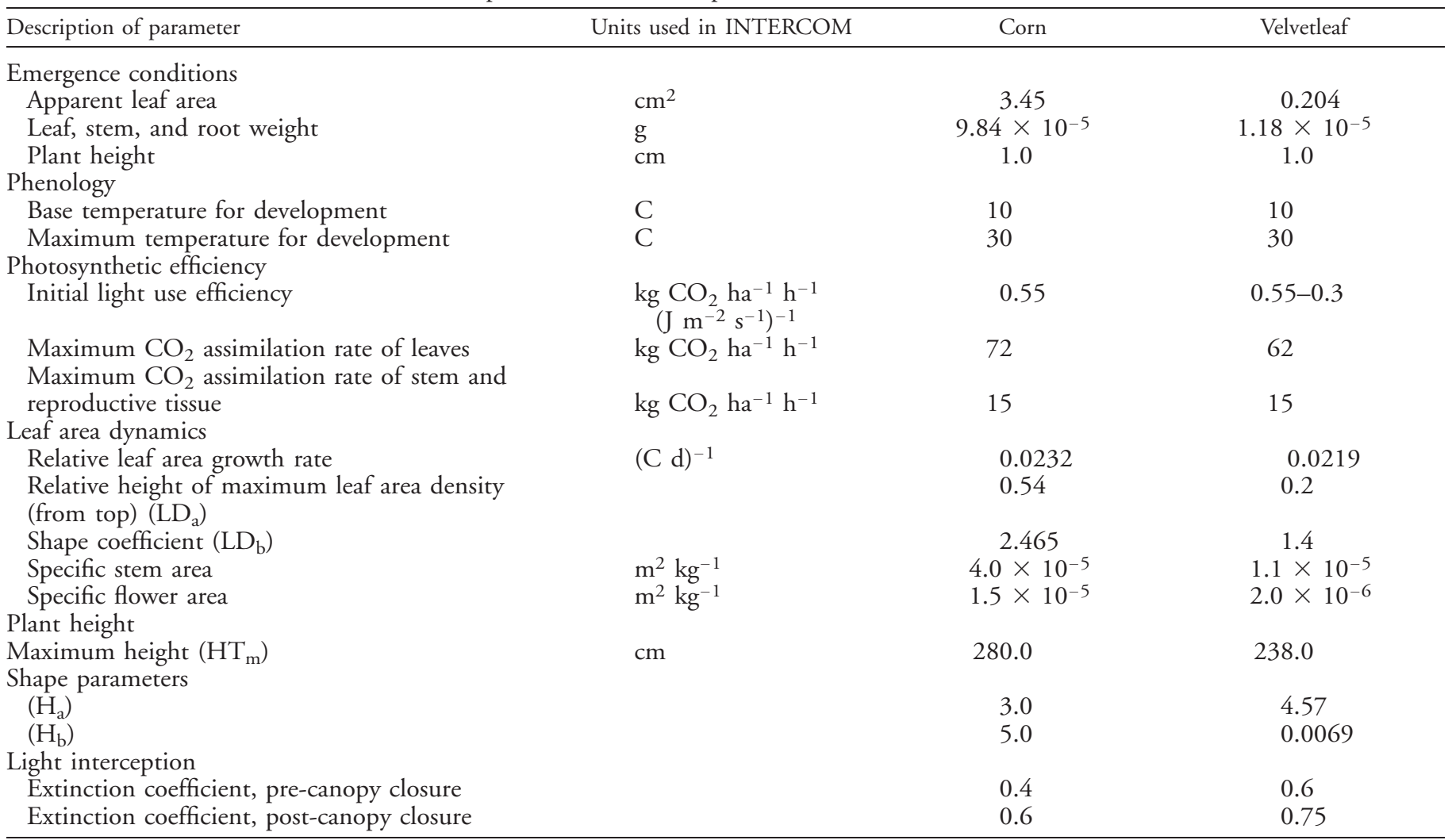

Model predictive ability was evaluated by comparing simulated and observed corn aboveground biomass, LAI, grain yield, corn-velvetleaf yield loss relationships, and $\mathrm{T}_{\mathrm{e}}$ values. Several quantitative measures of accuracy were calculated where appropriate. The modeling efficiency (ME) (Janssen and Heuberger 1995) is similar to an $r^{2}$ in regression analysis but has no lower bound. A plot of normalized deviation $\left(\mathrm{P}_{i}-\mathrm{O}_{i}\right) / \mathrm{O}_{i}$, where $\mathrm{P}_{i}$ is the predicted value and $\mathrm{O}_{i}$ is the observed value) vs. the observed value provides a useful picture of patterns in predictive ability (Mitchell 1997). The average of these normalized deviations (average error, AE) provides an estimate similar to the coefficient of variation. For predicting yield loss relationships, INTERCOM also was compared to the regression of observed yield loss on velvetleaf density (Cousens 1985) by testing for equality of the residual mean square error (RMSE) using an $F$ test (Montgomery 1991). Finally, where appropriate, mean predicted and observed values were compared using a two-sample $t$ test, assuming unequal variances (Caton et al. 1999b).

\section{Results and Discussion}

\section{Monoculture Corn Biomass, LAI, and Weed-Free Yield}

Simulation of total aboveground biomass of corn was more accurate in 1997 than in 1998 (Figure 2). Final biomass was substantially underpredicted at maturity in 1998,

TABLE 3. Estimates of $I$ and $A$ and the resulting residual mean square error (RMSE) obtained by fitting observed and simulated percent yield loss on velvetleaf density using Cousens (1985) equation, probability value (P) for the test of RMSE $\mathrm{sim}=\mathrm{RMSE}_{\mathrm{obs}}$, modeling efficiency (ME) for yield loss prediction across all velvetleaf densities, and normalized average error (AE).

\begin{tabular}{|c|c|c|c|c|c|c|c|c|c|c|c|}
\hline Site & & Year & $I_{\mathrm{obs}}$ & $A_{\text {obs }}$ & RMSE $_{\text {obs }}$ & $I_{\text {sim }}$ & $A_{\text {sim }}$ & RMSE $_{\text {sim }}$ & $\mathrm{P}$ & $\mathrm{ME}$ & $\mathrm{AE}$ \\
\hline \multirow[t]{5}{*}{ NE } & (Lincoln) & 1988 & 11.4 & 100 & 315.1 & 12.4 & 85.0 & 318.9 & 0.49 & 0.73 & -0.20 \\
\hline & (Lincoln) & 1991 & 12.0 & 78.9 & 189.4 & 34.9 & 92.2 & 589.9 & 0.01 & 0.18 & 0.33 \\
\hline & (Lincoln) & 1992 & 9.6 & 50.9 & 69.9 & 22.0 & 73.3 & 329.0 & 0.00 & -0.19 & 0.71 \\
\hline & (Mead) & 1995 & 33.8 & 60.9 & 76.9 & 18.9 & 82.9 & 154.9 & 0.09 & 0.72 & -0.09 \\
\hline & (Mead) & 1996 & 7.5 & 59.5 & 98.8 & 20.9 & 80.7 & 430.5 & 0.00 & -0.38 & 0.49 \\
\hline SD & (Brookings, 1) & 1992 & 4.7 & 33.1 & 88.2 & 3.8 & 33.8 & 168.8 & 0.03 & 0.30 & -0.53 \\
\hline \multirow[t]{2}{*}{ MI } & (East Lansing) & 1992 & 2.8 & 38.0 & 52.0 & 6.4 & 51.8 & 52.7 & 0.49 & 0.57 & -0.20 \\
\hline & & 1993 & 5.3 & 38.0 & 24.7 & 2.7 & 21.5 & 45.4 & 0.07 & 0.58 & -0.46 \\
\hline \multirow[t]{2}{*}{$\mathrm{CO}$} & (Fort Collins) & 1993 & 14.3 & 60.0 & 46.3 & 6.4 & 29.5 & 326.5 & 0.00 & -0.33 & -0.75 \\
\hline & & 1994 & 14.3 & 60.0 & 46.3 & 9.1 & 48.4 & 182.8 & 0.00 & 0.53 & -0.46 \\
\hline
\end{tabular}




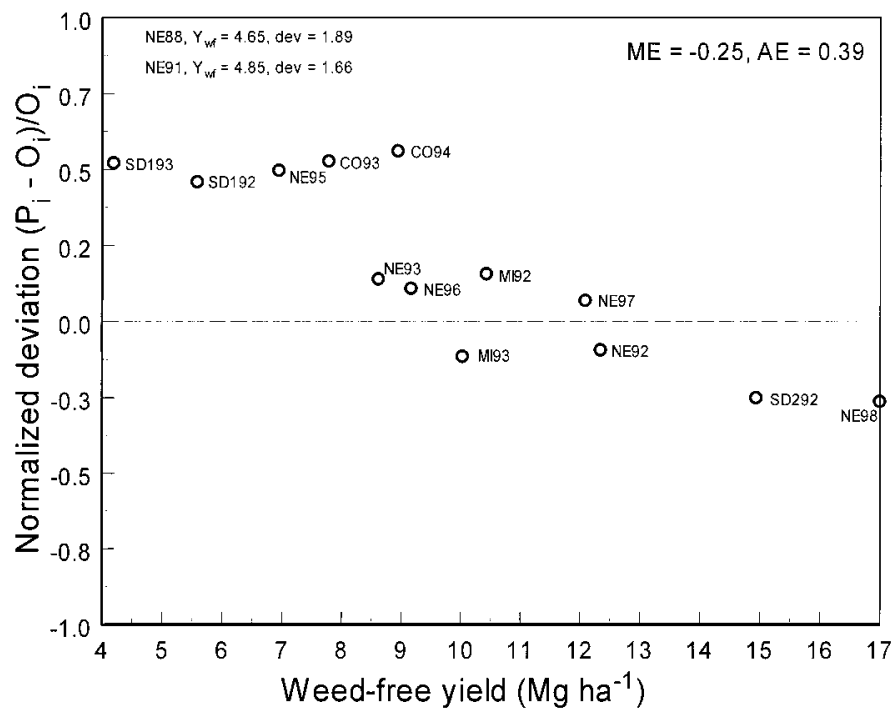

FIGURE 3. Normalized deviation between simulated $\left(\mathrm{P}_{i}\right)$ and observed $\left(\mathrm{O}_{i}\right)$ weed-free yield in relation to observed weed-free yield. ME, modeling efficiency; AE, average normalized error across all yields.

perhaps because our empirical partitioning coefficients were obtained from data where corn yield ranged from 6 to 9 $\mathrm{Mg} \mathrm{ha}^{-1}$ and do not adequately account for partitioning to reproductive yield under optimal conditions $(>15 \mathrm{Mg}$ $\left.\mathrm{ha}^{-1}\right)$. Overall mean observed and simulated total aboveground biomass and LAI did not differ in either year $(\mathrm{P}=$ 0.79 and 0.89 for 1997 and 1998, respectively). Simulation of monoculture corn LAI was overpredicted by an average of $9 \%$ in 1997 , but underpredicted by an average of $31 \%$ in 1998. The larger deviation in 1998 may be the result of inaccurate values of specific leaf area under near-optimal production conditions.

Prediction of weed-free yield was most accurate within the range of 8 to $13 \mathrm{Mg} \mathrm{ha}^{-1}$. Weed-free yield was overpredicted when observed yields were less than $8 \mathrm{Mg} \mathrm{ha}^{-1}$ and underpredicted at yield levels greater than $13 \mathrm{Mg} \mathrm{ha}^{-1}$ (Figure 3). Overprediction of yield at less than $8 \mathrm{Mg} \mathrm{ha}^{-1}$ was expected at NE88 and NE91 because these data were obtained under rain-fed conditions in drought years. The other environments where weed-free yield was overpredicted had high temperatures during reproduction (NE95) (Lindquist and Mortensen 1999) or had generally more arid climatic conditions (greater vapor pressure deficit, CO93, CO94, SD192, and SD193). The overpredicted yield in these environments may be the result of a response of corn during reproductive development to high temperature stress or of a $\mathrm{CO}_{2}$ assimilation response to vapor pressure deficit (VPD) (Bunce 1982; El-Sharkawy et al. 1985; Morison and Gifford 1983), neither of which are currently accounted for in the model. Reasons for underprediction of yield at higher productivity levels were not clear but may be because of the use of inaccurate values for partitioning and specific leaf area under near-optimal production conditions.

\section{Yield Loss-Velvetleaf Density Relationships}

Depending on the performance criterion used, prediction of corn yield loss may be considered accurate across the full range of velvetleaf density for 5 to 9 of the 13 data sets (Table 3; Figure 4). Using an arbitrary ME value of 0.5 (Caton et al. 1999b), yield loss was predicted accurately for only 5 of the 13 data sets (Table 3). Assuming that the average deviation (AE) across all predicted and observed val-

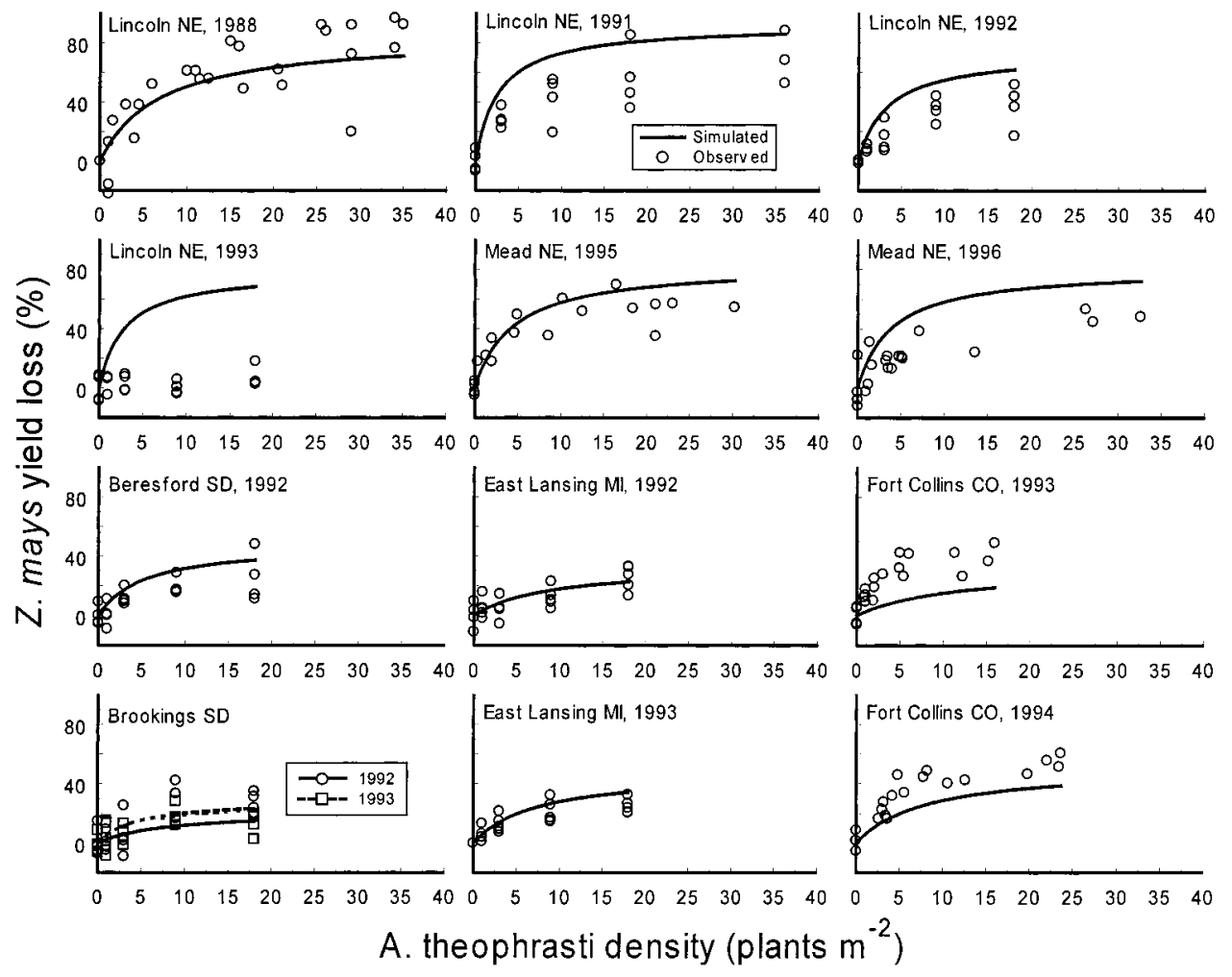

Figure 4. Observed (symbols) and simulated (lines) percent corn yield loss as a function of velvetleaf density for 13 site-locations across the north-central United States. 


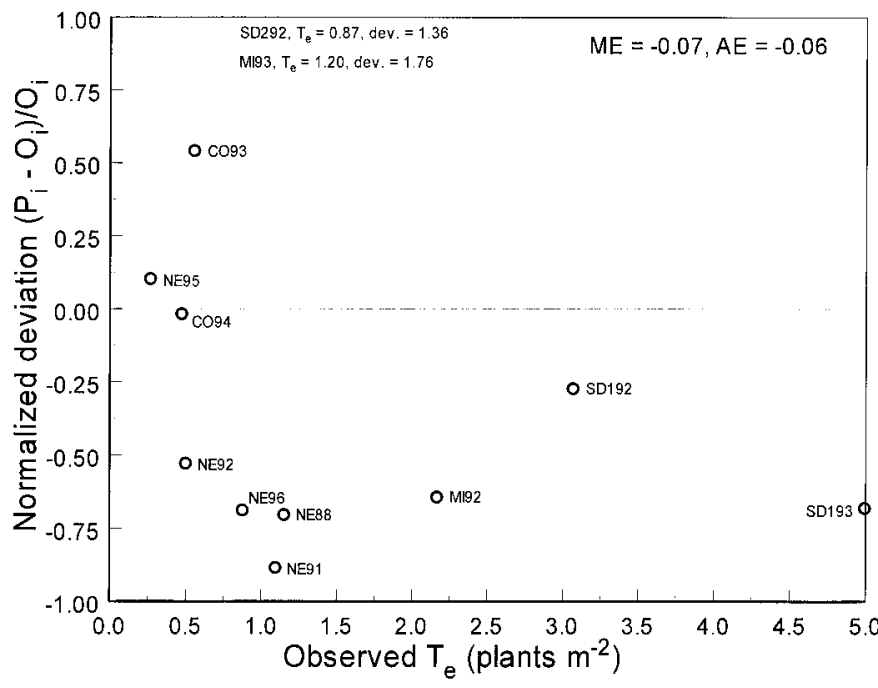

FIGURE 5. Normalized deviation between simulated $\left(\mathrm{P}_{j}\right)$ and observed $\left(\mathrm{O}_{i}\right)$ single-year economic threshold velvetleaf density $\left(\mathrm{T}_{\mathrm{e}}\right)$ in relation to observed $\mathrm{T}_{\mathrm{e}} . \mathrm{T}_{\mathrm{e}}$ was calculated by solving Equation 3 (using estimates of $I$ and $A$ from Table 3). ME, modeling efficiency; AE, average normalized error across all observed $\mathrm{T}_{\mathrm{e}}$.

ues must be less than $|0.5|$, yield loss was predicted accurately for 9 of the 13 data sets. INTERCOM predicted yield loss similarly to the best fitted empirical regression model for 6 of the 13 data sets (Table 3).

Velvetleaf did not cause yield loss in the 1993 Nebraska experiment, whereas INTERCOM predicted relatively large yield losses at all velvetleaf densities. The total lack of yield loss in this experiment may have been the result of a fungal infection (Verticillium spp.) in velvetleaf brought on by the cool, wet conditions that year (Lindquist et al. 1996). This would explain the large discrepancy between predicted and observed yield loss because the model does not account for the effects of disease or insect pests on either corn or velvetleaf.

Aside from the NE93 data set, greatest deviations between predicted and observed yield loss occurred at NE91, NE92, NE96, where yield loss was overpredicted, and at CO93, where yield loss was underpredicted. The reasons for inaccurate predictions at these locations are not clear but may be due in part to a differential response of corn and velvetleaf to temperature, vapor pressure deficit, and water supply.

\section{Single-Year Economic Threshold Velvetleaf Density $\left(T_{e}\right)$}

Estimates of the single-year economic threshold velvetleaf density $\left(\mathrm{T}_{\mathrm{e}}\right)$ calculated from INTERCOM-predicted weedfree yield and yield loss were an average of $6 \%$ smaller than those calculated from observed data (Figure 5). Therefore, INTERCOM predicted a conservative value of $T_{e}$ in most cases, indicating that it may be a useful tool for predicting single-year economic threshold weed densities at various locations. However, there appears to be no clear pattern as to when $T_{e}$ is poorly predicted, probably because the model is not consistent in where it fails. In other words, weed-free yield is poorly predicted in fairly predictable (high-stress and near-optimal) location-years. However, predicted and observed yield loss because of velvetleaf interference agreed quite well in some location-years where weed-free yield was poorly predicted (e.g., NE88, SD192, SD193), but not at others (e.g., NE91). Moreover, in some cases where predicted and observed weed-free yield agreed well, predicted and observed yield loss did not (e.g., NE92, NE96). These results implicate two distinct problem areas within the model. The model appears to fail at predicting weed-free yield primarily under high-stress conditions. However, its failure at predicting yield loss due to velvetleaf interference may be because of more subtle differences in response of the two species to even nonstress conditions. Improving the capacity of INTERCOM to predict $T_{e}$ will require improvements in its ability to predict both weed-free yield and yield loss relationships.

Results of this analysis are encouraging because model predictions and observed values agreed well for monoculture-grown corn LAI and total aboveground biomass. Moreover, predicted and observed corn weed-free yield and yield loss in mixture agreed well for several years and locations. Results indicate that INTERCOM may be useful for predicting variation in yield loss-weed density relationships and the single year economic threshold weed density. However, improvements are needed for reliable prediction of weedfree yield, yield loss, and $T_{e}$.

Immediate improvements in model performance could be made if accurate data on crop and weed density and their dates of emergence, anthesis, and maturity were reported with every crop-weed interference study. Further improvements could be made by incorporating the effects of various stress factors (high temperature, VPD, water and nitrogen stress, etc.) on both crop and weed growth and competitive ability. Unfortunately, incorporating such improvements will require a substantial investment in further research on the comparative ecophysiology of these and other crop and weed species.

\section{Acknowledgments}

Contribution of the University of Nebraska Agricultural Research Division Journal Series 12602. This research was supported in part by CSREES Regional Project NC202 "A Biological and Ecological Basis for a Weed Management Model to Reduce Herbicide Use in Corn," USDA NRICGP grant 95-37315-2049 and USDA NRICGP Grant 97-00785.

\section{Literature Cited}

Boote, K. J., J. W. Jones, and N. B. Pickering. 1996. Potential uses and limitations of crop models. Agron. J. 88:704-716.

Bridges, D. C. 1992. Crop Losses Due to Weeds in the United States1992. Weed Science Society of America. pp. 75-147.

Bunce, J. A. 1982. Low humidity effects on photosynthesis in single leaves of $\mathrm{C}_{4}$ plants. Oecologia 54:233-235.

Cardina, J., E. Regnier, and D. Sparrow. 1995. Velvetleaf (Abutilon theophrasti) competition and economic thresholds in conventional and notillage corn (Zea mays). Weed Sci. 43:81-87.

Caton, B. P., T. C. Foin, and J. E. Hill. 1999a. A plant growth model for integrated weed management in direct-seeded rice. I. Development and sensitivity analyses of monoculture growth. Field Crops Res. 62: $129-143$.

Caton, B. P., T. C. Foin, and J. E. Hill. 1999b. A plant growth model for integrated weed management in direct-seeded rice. II. Validation testing of water-depth effects and monoculture growth. Field Crops Res. 62:145-155.

Caton, B. P., T. C. Foin, and J. E. Hill. 1999c. A plant growth model for integrated weed management in direct-seeded rice. III. Interspecific competition for light. Field Crops Res. 63:47-61. 
Coble, H. D. and D. A. Mortensen. 1992. The threshold concept and its application to weed science. Weed Technol. 6:191-195.

Coleman, J. S., L. Rochefort, F. A. Bazzaz, and F. I. Woodward. 1991. Atmospheric $\mathrm{CO}_{2}$, plant nitrogen status and the susceptibility of plants to an acute increase in temperature. Plant Cell Environ. 14: 667-674.

Cousens, R. 1985. A simple model relating yield loss to weed density. Ann. Appl. Biol. 107:239-252.

Cousens, R. 1987. Theory and reality of weed control thresholds. Plant Prot. Q. 2:13-20.

de Wit, C. T., J. Goudriaan, H. H. van Laar, F.W.T. Penning de Vries, R. Rabbinge, H. van Keulen, L. Sibma, and C. de Jonge. 1978. Simulation of Assimilation, Respiration and Transpiration of Crops. Simulation Monographs. Wageningen, The Netherlands: Pudoc. p. 35.

El-Sharkawy, A. M., J. H. Cock, and A. Del Pilar Hernandez. 1985. Stomatal response to air humidity and its relation to stomatal density in a wide range of warm climate species. Photosynth. Res. 7:137-149.

Graf, B., A. P. Gutierrez, O. Rakotobe, P. Zahner, and W. Delucchi. 1990. A simulation model for the dynamics of rice growth and development: Part II-The competition with weeds for nitrogen and light. Agric. Syst. 32:367-392.

Graf, B. and J. E. Hill. 1992. Modelling the competition for light and nitrogen between rice and Echinochloa crus-galli. Agric. Syst. 40:345359.

Janssen, P.H.M. and P.S.C. Heuberger. 1995. Calibration of process-oriented models. Ecol. Model. 83:55-66.

Jordan, N. 1992. Weed demography and population dynamics: implications for threshold management. Weed Technol. 6:184-190.

Kiniry, J. R., J. R. Williams, P. W. Gassman, and P. Debaeke. 1992. A general, process oriented model for two competing plant species. Trans. Am. Soc. Agric. Eng. 35:801-810.

Kiniry, J. R., J. R. Williams, R. L. Vanderlip, J. D. Atwood, D. C. Reicosky, J. Mulliken, W. J. Cox, H. J. Mascagni, S. E. Hollinger, and W. J. Wiebold. 1997. Evaluation of two maize models for nine U.S. locations. Agron. J. 89:421-426.

Knezevic, S. Z., S. F. Weise, and C. J. Swanton. 1994. Interference of redroot pigweed (Amaranthus retroflexus L.) in corn (Zea mays L.). Weed Sci. 42:568-573.

Knezevic, S. Z., S. F. Weise, and C. J. Swanton. 1995. Comparison of empirical models depicting density of Amaranthus retroflexus L. and relative leaf area as predictors of yield loss in maize (Zea mays L.). Weed Res. 35:207-214.

Kropff, M. J. 1993. Mechanisms of competition for light. Pages 33-61 in M. J. Kropff and H. H. van Laar, eds. Modelling Crop-Weed Interactions. Wallingford, Great Britain: CAB International and International Rice Research Institute.

Kropff, M. J., K. Moody, J. L. Lindquist, T. R. Migo, and F. F. Fajardo. 1994. Models to predict yield loss due to weeds in rice ecosystems. Philipp. J. Weed Sci. (Special Issue):29-44.

Kropff, M. J. and C.J.T. Spitters. 1992. An eco-physiological model for interspecific competition, applied to the influence of Chenopodium album L. on sugar beet. I. Model description and parameterization. Weed Res. 32:437-450.

Kropff, M. J., C.J.T. Spitters, B. J. Schnieders, W. Joenje, and W. de Groot. 1992. An eco-physiological model for interspecific competition, applied to the influence of Chenopodium album L. on sugar beet. II. Model evaluation. Weed Res. 32:451-464.

Kropff, M. J. and H. H. van Laar. 1993. Modelling crop-weed interactions. Wallingford, Great Britain: CAB International and International Rice Research Institute. $274 \mathrm{p}$.

Lindquist, J. L. and M. J. Kropff. 1996. Applications of an ecophysiological model for irrigated rice (Oryza sativa)-Echinochloa competition. Weed Sci. 44:52-56.

Lindquist, J. L. and D. A. Mortensen. 1998. Tolerance and velvetleaf (Abutilon theophrasti) suppressive ability of two old and two modern corn (Zea mays) hybrids. Weed Sci. 46:569-574.

Lindquist, J. L. and D. A. Mortensen. 1999. Ecophysiological characteristics of four maize hybrids and Abutilon theophrasti. Weed Res. 39: $271-285$.

Lindquist, J. L., D. A. Mortensen, S. A. Clay, R. Schmenk, J. J. Kells, K. Howatt, and P. Westra. 1996. Stability of corn (Zea mays)-velvetleaf (Abutilon theophrasti) interference relationships. Weed Sci. 44:309313.

Lindquist, J. L., D. A. Mortensen, P. Westra, et al. 1999. Stability of corn (Zea mays)-foxtail (Setaria spp.) interference relationships. Weed Sci. 47:195-200.

Maxwell, B. D. 1992. Weed thresholds: the space component and considerations for herbicide resistance. Weed Technol. 6:205-212.

Mitchell, P. L. 1997. Misuse of regression for empirical validation of models. Agric. Syst. 54:313-326.

Montgomery, D. C. 1991. Design and analysis of experiments. 3rd ed. New York: J. Wiley. pp. 42-45.

Morison, J.I.L. and R. M. Gifford. 1983. Stomatal sensitivity to carbon dioxide and humidity. Plant Physiol. 71:789-796.

Patterson, D. T. 1992. Temperature and canopy development of velvetleaf (Abutilon theophrasti) and soybean (Glycine max). Weed Technol. 6: 68-76.

Ryel, R., P. W. Barnes, W. Beyschlag, M. M. Caldwell, and S. D. Flint. 1990. Plant competition for light analyzed with a multispecies canopy model. I. Model development and influence of enhanced UV-B conditions on photosynthesis in mixed wheat and wild oat canopies. Oecologia 82:304-310.

Swinton, S. M. and R. P. King. 1994. A bioeconomic model for weed management in corn and soybean. Agric. Syst. 44:313-335.

Tollenaar, M. 1989. Response of dry matter accumulation in maize to temperature: II. Leaf photosynthesis. Crop Sci. 29:1275-1279.

Wilkerson, G. G., J. W. Jones, H. D. Coble, and J. L. Gunsolus. 1990. SOYWEED: a simulation model of soybean and common cocklebur growth and competition. Agron. J. 82:1003-1010.

Received May 2, 2000, and approved October 17, 2000. 